\title{
1 Consumer perceptions of indulgence: a case study with cookies
}

2

3 Amparo Tarrega, Johanna Marcano and Susana Fiszman*

4

5

6 Instituto de Agroquímica y Tecnología de Alimentos (IATA-CSIC), Agustín Escardino 7, 7 46980, Paterna, Valencia, Spain

8

$9 \quad$ *corresponding author: Susana Fiszman, E-mail address: sfiszman@iata.csic.es

10 Phone number: (+34) 963900022

11

12 Key words: indulgence, projective mapping, package, CATA, eating motivation, eating 13 occasion

14 
Food indulgence has been widely studied in psychology and related sciences. However, how it is perceived by consumers has rarely been examined in the field of Food Science. This paper presents a case study with 17 different types of cookies. Two different exploratory studies were performed with two groups of consumers. In the first, 90 consumers performed projective mappings, placing the samples according to the similarities or differences they found a) based on the packaging alone and b) based on tasting alone (the tasks were performed one month apart). The consumers were also asked to describe the single packages/cookies and groups of packages/cookies on the map. The maps obtained from the packaging and tasting tasks were fairly similar, indicating that in general the images, information, and package design raised expectations that were confirmed upon tasting the cookies. Qualitative analysis of the terms used to describe the maps of the two scenarios showed that chocolate (dark or milk) and type of cookie were the principal classification factors, while less or no importance was placed on energy content or uses. Consequently, in the second study 8 of the initial 17 cookies were selected as representing the 8 cookie types detected through separate hierarchical clustering analyses of the results from the package and cookie scenarios. A group of 100 consumers tasted each type of cookie, scored them on "acceptability," "perceived healthiness," and "familiarity," and answered a CATA questionnaire listing eating motivations and occasions. 
42 A food product is not indulgent per se; "indulgence" is related to consumers' inner motivations and is a primary driver of consumption of so-called "indulgent food," which has its own place in the market. According to Luomala et al. (2004), food is one of the most fundamental sources of hedonic experiences in human life. Even though there is an increased awareness of healthy eating, consumers will always allow themselves to indulge from time to time. Merriam-Webster's dictionary (Merriam-Webster, 2016) defines indulgence as: 1 . the behavior or attitude of people who allow themselves to do what they want; 2 . the act of doing something that you enjoy, but that is usually thought of as wrong or unhealthy; 3. something that is done or enjoyed as a special pleasure. Whereas the first meaning does not directly imply any negative connotation, the second one introduces the concept of "despite," in other words "sacrificing this to obtain that." Looking at the synonyms for indulgence proposed by the same dictionary ("benevolence, boon, courtesy, grace, favor, kindness, mercy, service, turn"), there seem to be no negative consequences of indulgence, but looking at the antonyms proposed ("basic, essential, fundamental, must, necessity, requirement"), their opposite again presents the item obtained as unnecessary. Transferring these concepts to the context of food, indulgence is inescapably associated with unhealthy and caloric, but tasty. Cheng, Huang, Chuang, and Ju (2015) stated that food indulgence is subtle and difficult to observe. While there is no single definition of "indulgent food," consumers recognize it when they see, smell and taste it (Cargill, 2017), and consider it highly pleasurable. Some concepts that have been related to foods for indulgent consumption are: a way to satisfy cravings, pursue hedonism, splurge on special occasions, enjoy premium products, experiment with food culture, and use food as a status symbol (Palmer, 2008). In turn, indulgence in food products is related to timepressured, stressed, and tired consumers seeking pleasure, relaxation or self-reward. According to Pool, Brosch, Delplanque, and Sander (2014) stress can increase reward pursuits, traditionally seen as an attempt to relieve negative affect through the hedonic properties of a reward. However, reward pursuit is not always proportional to the pleasure experienced, because reward processing involves distinct components, 
including the motivation to obtain a reward (i.e. wanting) and the hedonic pleasure experienced during consumption of the reward (i.e. liking).

In this context, ascertaining the occasions and motivations that consumers identify for food products associated with indulgence could greatly enhance our knowledge concerning this area of food product development.

It is not surprising that a large body of research dealing with indulgence comes from psychology, marketing and related fields. Studies on indulgent consumption have investigated the effect of a number of factors, including the perception of deservingness (Cavannaugh, 2014), the pressure of public scrutiny (Cheng, et al., 2015), the influence of impulsive personality traits (Ramanathan \& Williams, 2007), positive or negative mood (Gardner, Wansink, Kim \& Park, 2014), and impulsive buying (Miao, \& Mattila, 2013), among others.

However, research on food products designed "for a treat" and how consumers perceive them is scarce in Food Science and Technology literature. This may be due to recent and current trends toward the development of healthy options. Nonetheless, indulgence food products occupy a place in the market and their sensory space is worth studying.

Within the framework of qualitative research, projective mapping has become increasingly popular for investigating and trying to understand consumer attitudes (Vidal, Ares, \& Giménez, 2013) as it allows (dis)similarities within a set of products to be collected with a holistic sample approach (Dehlholm, 2014). As a case study, the present authors considered it would be interesting to apply this technique to a broad, but deliberate selection of cookies as an example of indulgence products belonging to the same food category. Despite the fact that all the products were considered to be cookies, they constituted a very inhomogeneous sample set due to the variety of their ingredients and compositions. In such cases, it is essential for consumers to have a holistic perception. The dimensions obtained should provide a wealth of information about the structure of the sensory space of cookies for indulgence in the consumers' minds. In addition, exploring the consumers' inner motivations and occasions for eating cookies might provide further insight into this food category, which could be a valuable aid to food developers. 
103 Check all that apply (CATA) has been identified as a method that allows multiple options to be selected. Consumers are presented with a list of terms and asked to indicate which words or phrases appropriately describe their experience with the sample being evaluated. The terms might include not only sensory attributes but also emotional responses, purchase intention, potential applications, or product positioning (Meyners \& Castura, 2014).

The aim of the present study was to investigate consumer perceptions of a broad set of cookies in two different scenarios: considering only the packaging and tasting the cookies under blind conditions. In addition, analyses of indulgence as a driver of motivations and occasions for cookie consumption, and its relation to acceptability, familiarity, and perceived healthiness would contribute to understanding the sensory space of this food category.

\section{MATERIALS AND METHODS}

\subsection{Samples}

118 The samples consisted of 17 types of cookies, all containing appealing ingredients (chocolate, almonds, cream layers, etc.), bought in several local supermarkets. All the products displayed the nutritional facts and the list of ingredients on the package in accordance with the font size and specifications of current European legislation. Three tables were drawn up to describe the samples. Table 1 lists the denomination, and information for each cookie given by the manufacturer on the front of the package, as well as the images shown (all 17 packages showed pictures of the cookies). In addition, this table gives the simplified codes (from 1 to 17) used to identify the samples throughout the present paper. Supplementary Table A gives any extra description or information about the cookie composition shown on other parts of the package. The 17 packages and 17 types of cookies were used in the two parts of Study 1, respectively (see below).

\subsection{Sensory tests}

132 Two studies were conducted. 
135 Study 1 was conducted in two separate parts, one month apart, with the same 90 consumers. In the first part, the participants only assessed the 17 cookie packages.

137 After one month, in the second part of the test, they evaluated the 17 cookies under 138 blind conditions (without the packages). In each part of the test, the samples were coded with random 3-digit numbers and were identified using stickers. The numbers were different in the two parts of the test. The consumers were provided with a pen and a size-A0 sheet of paper and were instructed to examine the packages / taste the cookies and place them on the sheet of paper according to their similarities and differences. They were told to place the samples they considered similar near each other and the samples they perceived as different at a distance from each other. All the participants were instructed to use the entire surface of the paper. They were free to examine the samples (observe, read, and handle the packages in the first part of the test, and observe and taste the cookies in the second part) in any order and as many times as they wanted. After placing the samples on the sheet of paper, the consumers had to write down the terms that described each sample or group of samples, with no time limit for completing the task (Marcano, Ares, \& Fiszman, 2015). The consumers took between 15 and 30 minutes to complete each projective mapping task.

152 During the tests, the participants' privacy and comfort were guaranteed in the spaces set aside for the activities. In the second part of the test, bottled water was available for rinsing between samples, but this was not obligatory.

2.2.2 Study 2. Acceptability, familiarity, perception of healthiness, and occasions and motivations for eating cookies

158 The acceptability and familiarity of 8 selected cookies (samples 3, 4, 5, 7, 8, 10, 11, and 14, representing different types of cookies) (Table 1), and how healthy the consumers considered them to be, were evaluated by 100 consumers (a different group from that in Study 1). Acceptability and perceived healthiness were assessed using nine-point scales (from Dislike extremely to Like extremely and from Very unhealthy to Very healthy), and familiarity was assessed on a continuous line scale (from $0=$ Very unfamiliar to 10 = Very familiar). To discover the occasions and motivations for consuming each type of cookie, after observing and tasting the cookie the participants were asked to answer two CATA questions: "Please tick all the motivations for you to 
eat this cookie" and "Please tick all the occasions when you would eat this cookie." The list of terms (Supplementary Tables B and C) was adapted from Jack, O'Neill, Piacentini, and Schrödder (1997), who compared the suitability of a number of fruit pieces and savory snacks for different uses. The lists of motivations and eating occasions presented in the CATA questionnaire were randomized across the consumers, but not across the samples.

\subsection{Consumers}

The consumers who participated in the two studies were recruited from the staff and student body of the Institute of Agrochemistry and Food Technology (IATA-CSIC) and the Polytechnic University of Valencia, who consumed cookies at least twice a week. Study 1 was conducted with 90 consumers, 58 women and 32 men, with ages ranging between 23 and 67 years. Study 2 was conducted with 100 consumers, 68 women and 32 men, with ages ranging from 19 to 63 years, none of whom had participated in Study 1.

\subsection{Data analysis}

184 The abscissa $(X)$ and ordinate $(Y)$ values of each sample on each consumer's sheet of paper were determined, taking the bottom left-hand corner of the sheet as the origin of the coordinates $(0,0)$. The data from the two sets of 90 projective mappings (packages and cookies) were analyzed separately using Multiple Factor Analysis (MFA) (Ares, Deliza, Barreiro, Giménez, \& Gámbaro, 2010). For MFA, the coordinates of each consumer were considered a separate group of variables (Pagès, 2005). The words elicited from the consumers in the descriptive phase were analyzed qualitatively by two independent researchers, grouping words with similar meanings into categories. After evaluating the words individually, the two researchers met to determine the final categories by consensus. The frequency with which each category was mentioned when describing each of the samples was measured; this frequency table was then used as a group of supplementary variables in the MFA (Pagès, 2005). The sample configurations obtained in the first four dimensions of the MFA for each scenario were compared using the RV coefficient. As this coefficient depends on the relative position of the points in the configuration, it is dependent on rotation and translation (Robert \& 
199 Escoufier, 1976). Its value is 0 if the configurations are uncorrelated and 1 if the 200 configurations are homothetic. In addition, two hierarchical cluster analyses (HCA) 201 were carried out to identify groups of samples in both the package and cookie 202 evaluations in Study 1. The analyses were performed on sample configurations in the 203 first four dimensions of the MFA, taking into account Euclidean distances and Ward's 204 aggregation criterion.

205 Mixed ANOVA (consumer as random factor and sample as fixed factor) were applied to 206 the acceptability, familiarity, and perceived healthiness data. Post-hoc Tukey tests were carried out to determine significant differences between samples. For each eating motivation and occasion answer to the CATA questions, Cochran's $Q$ test was performed to determine the significance of differences among samples (Meyners, Castura, \& Carr, 2013) (Supplementary Tables B and C).

An MFA was applied to the data from the two CATA questions (cookie consumption motivations and occasions), including acceptability, familiarity, and perceived healthiness as supplementary variables. All these statistical analyses were performed with the XLStat 2016 package (Adinsoft, France).

\section{Results}

\subsection{Study 1. Projective mapping}

\subsubsection{Projective mapping with the cookie packages (package scenario)} The MFA plots corresponding to the task performed with the cookie packages alone are shown in Figures $1 \mathrm{~A}$ and $1 \mathrm{~B}$ (dimensions 1 and 2 ) and Figures $1 \mathrm{C}$ and $\mathrm{DD}$ (dimensions 3 and 4, which accounted for $64.70 \%$ of the variance: 40.82 and $23.88 \%$, respectively). The sample configuration (Figure $1 \mathrm{~A}$ ) shows that dimension 1 clearly separates the products containing chocolate (negative), including wafers filled with cocoa cream (sample 14), from the rest (positive). The two exceptions were sample 8, a thin wafer tartlet covered with white chocolate and filled with hazelnut cream, and sample 4, a jam-filled tartlet with dark chocolate topping, which were placed in the positive half of dimension 1 despite containing chocolate. On the far right of the first dimension was a group composed of samples 16 (made of puffed pastry), 7 (a pure butter shortbread cookie), and 17 (a thin butter cookie with almonds). 
231 The positive values of dimension 2 (Figure 1A) show two groups: the group in the left-

232 half (the "chocolate zone") was composed of samples 1, 2, and 3, all of which were

233 chocolate chip cookies, while the group in the right-half (the "no chocolate zone") was

234 composed of samples 4, 5, and 6, all of which contained some kind of fruit, whether in 235 jam or dried form.

236 The remaining cookies, all of which were layered or filled with something other than

237 fruit, were placed in the negative part of the second dimension.

238 Dimension 3 (Figure 1 C) separated the samples with layers, fillings, and coatings 239 (positive) from the rest (negative), which had a more homogeneous structure (even if 240 they contained chocolate chips or almonds, these were evenly distributed throughout 241 the cookie). Dimension 4 separated the three wafer cookie samples - 12 (hazelnut 242 filling and covered with dark chocolate), 14 (cocoa filling), and 15 (cream-flavored 243 filling) - and sample 16 (a traditional Spanish puffed-pastry cookie) from sample 8, an 244 Italian cookie that was possibly not well-known to Spanish consumers.

245 The description task performed after the projective mapping of the packages 246 generated 90 terms (Table 2, Figures 1B and 1D), which fell into two major categories: 247 Non-sensory (66 terms), which with 2127 mentions accounted for the $85.1 \%$ of the 248 total mentions, and Sensory (24 terms), which were mentioned 373 times, 249 corresponding to $14.9 \%$ of the total mentions.

250 The Non-sensory terms were grouped into five subcategories: 1) related to an 251 ingredient, 2) related to cookie type, 3) related to the consumption motivation or occasion, 4) related to the package characteristics, and 5) some hard-to-classify Other terms. Ingredients generated 14 terms with 1073 mentions, indicating the importance that the consumers placed on some cookie ingredients. The number of mentions of most of the terms differed significantly between samples. Some terms were mentioned many times for certain samples, implying a high contribution to the description of the cookie or group of cookies on the map. Chocolate was an especially important ingredient, since five terms (Chocolate, Dark chocolate, White chocolate, Chocolate chips, and Double chocolate) were mentioned numerous times for all samples containing chocolate, and Without chocolate was likewise mentioned, although less frequently, for cookies that did not contain this ingredient. The term Fruit/Jam was also mentioned frequently for the samples containing fruit $(4,5$, and 6$)$. 
263 The Type of cookie subcategory contained 9 terms (566 mentions), all with a 264 significantly different number of mentions between samples and a high number of 265 mentions for the samples corresponding to each type. Along with chocolate-related 266 terms, Type of cookie terms contributed considerably to describing the placement of 267 the cookie or group of cookies on the map. The Package characteristics subcategory 268 generated 17 terms, but only 118 mentions, and only Plastic, Paper, and Attractive had 269 significantly different frequencies of mention between samples. None of the Package 270 terms was mentioned frequently (i.e. at least 9 times or $10 \%$ of consumers for the 271 same sample), indicating that the terms within this subcategory were of little 272 importance in the minds of consumers and contributed little to describing the cookies' 273 positioning on the map. The subcategory Uses and Occasions showed the same trend 274 as Package: only For special occasions was mentioned more than 9 times, for sample 27516 , a traditional Christmas cookie, by $13 \%$ of the consumers.

276 Finally, the subcategory Other brought together terms related to the brand (known, 277 unknown, store brand, high quality), price (expensive, cheap), type of manufacture 278 (artisan, industrial), etc. None of these terms were mentioned a high number of times 279 for any sample, although in many cases the number of mentions differed significantly 280 between samples. It is worth noting that although the energy content of the cookies 281 was high (from 392 to $560 \mathrm{kcal} / 100 \mathrm{~g}$ ), the term High calorie was not mentioned often 282 (a maximum of 4 for the same cookie). Likewise, a low number of mentions was 283 observed for the terms Healthier and Unhealthy, with no more than 2 mentions for the 284 same cookie, meaning that these concepts were of no special concern or that little 285 attention was paid to them when describing the samples from the packaging alone. The Sensory category was divided into three subcategories: 1) Appearance, 2) Flavor/ texture, and 3) Hedonics. Since the task was performed solely with the cookie packages, it is not surprising that the subcategory Appearance generated the greatest number of sensory terms (most likely based on the cookie images, Table 1) and of mentions (Table 2). Flavor/texture and Hedonics generated 9 and 5 terms, respectively, but Hedonics terms were mentioned a greater number of times (145), indicating that the images and descriptions, present on all package samples (Table 1), elicited hedonic expectations. In general, none of the sensory-related terms were mentioned by more than $10 \%$ of the consumers for the same cookie (data not shown), which meant that 
sensory characteristics did not contribute to the position of any of the samples on the map in the package scenario.

\subsubsection{Projective mapping performed while tasting the cookies (cookie scenario)}

The MFA plots for the assessment performed while tasting the cookies are shown in Figures $2 \mathrm{~A}$ and $2 \mathrm{~B}$ (dimensions 1 and 2 ) and Figures $2 \mathrm{C}$ and 2D (dimensions 3 and 4), which accounted for $63.04 \%$ of the variance (41.82 and $21.22 \%$, respectively). These values are similar to those for the task performed with the packages alone. The configuration of the samples on the plots shows that dimension 1 (Figure 2A) again clearly separated the products containing chocolate (negative) from the rest (positive). The three chocolate chip cookies (samples 1, 2, and 3) were placed on the very left of the map, forming a tight group, and the simplest cookies with no chocolate, no layers and no fillings (samples 7,16 , and 17) were placed on the far right of the map.

The positive values of dimension 2 (Figure 2A) separated all the wafer cookies (samples $12,14,15$, and 8), those with chocolate tablets (samples 9 and 11), and the chocolate sandwich (sample 13) from the chocolate chip cookies (samples 1, 2, and 3) and those containing fruit (samples 4, 5, and 6), following a similar pattern to the map obtained in the package scenario.

314 Dimensions 3 and 4 (Figures 2C) clearly separated the groups by cookie type: the three layered wafers, regardless of whether or not they were coated in chocolate; the three containing fruit, the two with white chocolate, the two with dark chocolate (tablet and filling), the three chocolate chip cookies, and the three without chocolate.

318 The description task that followed the projective mapping performed while tasting the cookies generated 80 terms (Table 3, Figures 2B and 2D), which were grouped into the same two categories as in the package scenario: Non-sensory and Sensory. The former

321 (37 terms, 1770 mentions), corresponded to $65.9 \%$ of the total mentions, a lower percentage than for the package task. The Sensory category (41 terms, 914 mentions) accounted for $34.0 \%$ of the mentions.

324 The Non-sensory and Sensory terms were grouped into the same subcategories as those created for the terms identified from the descriptions given in the package task, 
except for the non-sensory subcategory "Package," which obviously disappeared in

327 this part of study 1.

328 Within the Non-sensory category, the terms included in the Ingredients and Type of 329 cookie subcategories were the same as in the package task, and the figures (in terms of both number of mentions and total mentions) were also very similar.

The Uses subcategory showed the same trend as in the package task. Finally, the Other subcategory contained half the number of terms elicited in the package task. None of the terms included in Other were mentioned often for any one sample, although the number of mentions for many of them differed significantly between samples. Within the Sensory category, Flavor/texture accounted for more than double the mentions of the other two sensory subcategories. It was also the sub-category that elicited the most terms overall. The participants made 501 mentions of 10 tasterelated and 17 texture-related terms, whereas in the Package task, fewer terms (9) were elicited overall and they were only mentioned 72 times (Table 2), which makes sense for a task in which the cookies were not tasted. Interestingly, the term Vanilla, which received 27 mentions in the package scenario (data not shown), all for sample 10 (where images of a vanilla flower and bean were shown on the front of the package), was not mentioned when consumers tasted the cookie without looking at the package. Regarding Appearance and Hedonics, the number of terms generated in the cookie description task was similar to those in the package task, but the number of mentions was much higher.

\subsection{Comparison between the package and cookie scenarios}

349 To compare how consumers differentiated between the samples in the two scenarios, the configurations of the samples in the first four dimensions of the MFAs were studied.

352 In the first analysis, RV gave a high value (0.91) between the two data matrices, indicating a high degree of agreement among the two configurations.

354 Secondly, two separate HCAs were performed (truncation criteria: 8 classes) to compare how the samples were grouped when seeing only the packages and when only tasting the cookies without seeing the package. These groups are given in Table 4. 
result of the projective mappings, where the criteria for classifying the samples seemed to be fairly similar in the two scenarios. Indeed, a closer comparison of the clusters indicated that three of them were actually identical. The first set of identical clusters contained samples 1, 2, and 3. These samples were all chocolate chip cookies, which were all grouped into one cluster even though one of them had a soft texture (sample 1). The second set of identical clusters was made up of samples 8 and 9, both with a visible amount of white chocolate. In these cases, although the appearance, texture, and kind of cookie were very different, it seems that the presence of white chocolate was enough for consumers to group them together, separate from other cookies with dark chocolate. Finally, the third set of identical clusters comprised samples 11 and 13. Both had a generous amount of dark chocolate, albeit not in the form of chips: sample 11 had a chocolate tablet over a plain cookie and sample 13 was a chocolate cookie sandwich. Here, too, both samples had different appearances and textures, but a large, dark chocolate layer seemed to be the main classifying factor.

372 The cluster composed of samples 4, 5, and 6 in the package scenario split into two 373 clusters in the cookie scenario. All three of these samples contained some kind of fruit, 374 but sample 4 was the only one with a layer of chocolate on top, so when the consumers tasted it, they perceived it as different from the other cookies containing fruit. Another similar case was that of samples 12, 14, and 15, which were all (different) cream wafer sandwiches. They formed a single cluster in the cookie scenario, but two different clusters in the package scenario, where samples 12 and 14 , both containing brownish creams (cocoa and hazelnut) remained together, but sample 15 , filled with a whitish cream (dairy-cream flavored) was placed apart. It seems that when the consumers tasted the sample they found the texture (wafer) of these cookies similar, and the flavor of the filling was of secondary importance. The remaining samples were those that contained no chocolate: $7,10,16$, and 17. These samples were grouped into two clusters, with sample 16 set apart in the package scenario, and sample 10 set apart in the cookie scenario. As already mentioned, sample 16 was frequently mentioned as "For special occasions" since it is a typical Christmas cookie, so the package probably influenced the consumers in this sense. Sample 10 had a vanilla filling and contained almonds, so when tasted, it was 
probably perceived as different from the rest of cookies in this group, which were plainer in both texture and flavor.

392 3.3. Study 2. Cookie consumption: acceptability, familiarity, healthiness perception, and eating motivations and occasions

394 Based on the clustering results, 8 different types of cookies were selected as representative of each cluster formed in the Cookie scenario (Table 4). The acceptability, familiarity, and perception of healthiness were assessed by 100 consumers. The mean acceptability values ranged from 5.1 to 7.5 , with only four samples presenting mean values above 6 (slightly liked) (Table 5). This could be because participants that were not consumers of a specific type of cookie or did not like a specific characteristic or ingredient (vanilla, butter, or fruit) probably gave that cookie lower scores, decreasing its mean acceptability score. The cookies that received the highest acceptability scores all contained chocolate (or cocoa cream), regardless of being very different cookie types. The pure butter shortbread cookie and the two cookies containing different forms of fruit obtained lower acceptability values, even though one of them (sample 4) had a chocolate topping, indicating that this type of combination is not well-accepted by consumers. The least-liked cookie was a sandwich with vanilla-flavored filling (sample 10). The mean perceived healthiness values were low, ranging from 2.9 to 5.4. There were few significant differences among samples, the two exceptions being sample 5, considered the healthiest (no chocolate, filled with dried fruit), and the least healthy, sample 8 (a very thin wafer filled with hazelnut cream and covered in white chocolate).

412 The mean familiarity values covered a very wide range, from 2.9 to 8.5. No identifiable trend related to acceptability or healthiness was found, except that the two cookies that were less familiar to consumers scored low for acceptability. It is well-known that familiarity is one of the most important drivers of preference for food products, mostly because it reduces product uncertainty and leads to a more likely match between expectations and product characteristics (Deliza, \& MacFie, 1996).

418 To gain insight into the eating motivations and occasions that consumers associate with each type of cookie and their relation to acceptability, familiarity and perceived healthiness, an MFA was applied to the CATA question results. Relevant variations 
421 within the products were detected. The first and second dimensions of the MFA plot

422 (Figure 3A, Supplementary Tables B and C) explained $51.64 \%$ and $23.80 \%$ of the 423 variability, respectively. A high number of motivations ("As a treat," "As a 424 compensation," "As a reward," "To relax," "When I feel depressed") were explained by 425 the first dimension. These motivations were highly correlated both with acceptability 426 and with the occasions "When I am alone," "Leisure," "At home," and "At night." In 427 Figure 3B, which gives the sample distribution, it can be seen that the best-liked 428 cookies (samples 3,8 and 11 , on the right side of the first dimension) were more 429 frequently associated with these motivations than the rest of the samples (which 430 appear to the left on the plot).

431 In the positive half of the first dimension, but also explained by the second dimension, 432 two separate groups of motivations appeared. The group with positive values in the 433 second dimension contained more practical and utilitarian motivations ("When I want 434 an easy-to-get sweet food," "When I want something filling," "When I want something 435 for energy," and "As a nibble"), and was associated with more common and everyday 436 eating occasions ("At breakfast," "At work," "For mid-morning," "For mid-afternoon," 437 and "With tea or coffee"). They were also correlated with both acceptability and 438 familiarity. These more utilitarian motivations were important for samples 3 and 11 439 (cookies with chocolate chips and with a chocolate tablet), which were well-liked and 440 highly familiar to consumers. Towards the negative values of the second dimension, a 441 third group of motivations had to do with low affordability ("When I want something 442 exclusive," "To afford a luxury," "When I want something prestigious") and social 443 occasions ("To celebrate," "To share"), and were associated with "As a dessert" and 444 "At night" as eating occasions. These motivations were specifically relevant for sample 4458 , a very thin wafer cookie filled with hazelnut cream and covered in white chocolate 446 that was one of the best-liked cookies, considered one of the unhealthiest, and 447 showed low familiarity. It was probably perceived as a very luxurious, sophisticated 448 cookie, since it elicited the highest frequency of mentions for exclusiveness-, luxury-, 449 and prestige-related motivations (Supplementary Table B).

450 The left side of the first dimension contained few motivations (Figure 3A). With 451 positive values in dimension 2 and highly correlated to healthiness, the motivations 452 "After doing exercise," "When I want something cheap," and "When I want something 
heathy" appeared. These motivations were especially important for sample 5 (the

454 fruit-filled cookie without chocolate) (Figure 3B), which was considered the healthiest

455 (Table 5). Sample 5, together with samples 7 and 14 (the all-butter shortbread and the 456 wafer filled with cocoa cream, both with significantly lower scores for perception of 457 healthiness than sample 5), in general showed the lowest frequency of exclusivity and 458 social motivation.

459 Finally, samples 4 (containing a fruit jam and topped with a chocolate layer) and 10 460 (vanilla cream sandwich) had low mean acceptability scores. In addition, the latter 461 obtained a very low mean score for familiarity (Table 5). Neither seemed to be 462 associated with any specific motivation or occasion compared to the other samples.

\section{Discussion}

465 Two studies were performed with cookies that contained especially "appealing" 466 ingredients such as chocolate, almonds, butter, cream layers, etc. (Table 1). In Study 1, projective mapping was performed with 17 different cookies in two different scenarios: 1) looking solely at the cookie packages and 2) tasting the cookies. In Study 2, acceptability, familiarity, and perception of healthiness were assessed for cookies representing the 8 principal cookie types sorted out by the consumers in Study 1 .

\subsection{Comparison of the projective mapping findings in the two scenarios}

473 The sample configuration plots for the cookie package task and the cookie tasting task 474 were similar.

475 Both sets of maps (Figures 1 A-D and 2 A-D) showed that, in general, the first 476 dimension separated cookies containing chocolate (or cocoa) from the rest. The participants considered that all these samples possess similarities regardless of the kind of chocolate/cocoa element (cream, tablet, chips) or the type of cookie dough

479 (wafer, normal cookie). For example, the two wafers filled with cocoa cream (samples 12 and 14, one of them covered with dark chocolate) were considered very similar and placed close together (Figure 1A) while the wafer filled with dairy cream-flavored cream was placed on the right side of the map, demonstrating that chocolate/cocoa was a more important classification factor than cookie type in the mind of the consumers. 
485 It is worth noting that white chocolate was not considered particularly similar to dark 486 or milk chocolate. In fact, in both the package and cookie scenarios, sample 9 (a cookie 487 with a white chocolate tablet) was placed close to another cookie with white chocolate 488 instead of close to sample 11, which was identical except for having a dark (instead of 489 a white) chocolate tablet.

490 Interestingly, several samples were placed in different halves of the maps (in the first 491 dimension) depending on the scenario. Sample 4, which contained both a fruit filling 492 and a chocolate topping, was placed in the "no chocolate half" of the package scenario 493 map but in the "chocolate half" of the cookie scenario map. The chocolate top layer 494 was probably the decisive factor in its placement when tasted. Similarly, sample 8, a 495 wafer tartlet filled with hazelnut cream and covered with white chocolate, moved into 496 the "chocolate zone" when the chocolate (although white) was perceived. In contrast, 497 the opposite occurred with sample 14, a wafer filled with cocoa cream (but with no 498 chocolate), which moved into the "no chocolate zone" when tasted. Taken together, 499 examples indicate that chocolate renders the samples similar to the consumers, who 500 place them in the same class.

501 The second factor that consumers considered important for grouping samples cookie 502 type. For example, the two samples containing fruit (but no chocolate) were 503 considered similar in the two scenarios regardless of the type or form of fruit (dried or 504 jam) or cookie dough, while the three simplest cookies (no fillings, no layers) formed 505 another group regardless of other characteristics such as dough type or texture.

506 Analysis of the terms used to describe the samples in the two scenarios indicated that 507 their elicitation followed a similar pattern. The kind and frequency of mention of the 508 sensory and non-sensory terms were similar except for a (logical) increase in the 509 number of mentions for sensory terms in the cookie scenario. This result indicated that 510 the images and description given on the packages allowed the consumers to obtain a 511 clear, precise idea of the products. The number of mentions confirmed that the 512 subcategories Ingredients (especially chocolate) and Type of cookie made an important 513 contribution to the mapping of the cookies in both scenarios.

514 In the cookie scenario, two kinds of terms that were present in the package scenario 515 disappeared: those related to the brand, even where the brand could be read on the 
516 cookie itself, and those related to perceptions of the price (cheap or expensive), as

517 these features are transmitted more efficiently by the package than by the cookie.

518 No mention of Unhealthy or High calorie was made in either the package or the cookie 519 scenario.

520

5214.2 Study 2. Cookie consumption: acceptability, familiarity, perception of healthiness, 522 and eating motivations and occasions

523 An interesting finding in Study 1 was that consumers did not spontaneously relate any 524 cookie to specific eating motivations. According to Kivetz \& Simonson (2002), in their 525 daily lives consumers distinguish between necessities, such as ordinary food and 526 health, and items that are nonessential and often pleasurable, representing 527 indulgence. This implies that food for indulgence may not be part of the normal, 528 everyday diet and that consequently, its consumption requires special motivations. 529 Many people eat in order to distract themselves from, compensate for, or cope with 530 negative affects such as stress, anxiety, frustration, fear, daily difficulties, sadness, 531 boredom, depression, and fatigue. The foods eaten under these circumstances are 532 sometimes referred to as comfort foods, and most of them are sweet, carbohydrate-

533 and fat-rich foods because such foods can provide immediate satisfaction (Gardner, 534 Wansink, Kim, \& Park, 2014).

535 In Study 2, to gain insight into consumer perceptions of different kinds of cookies, the 536 participants were asked to choose a series of motivations and occasions for consuming 537 each of the 8 cookies presented. The first dimension (Figure 3A) exhibited a 538 concentration of motivations that were highly correlated with each other and are 539 normally related to indulgence ("As a treat," "As a compensation," "As a reward," "To 540 relax," "When I feel depressed"), suggesting that they are part of the same concept. 541 Cavanaugh (2014) defined indulgence, in the context of consumer choice, as allowing 542 oneself to select and enjoy the pleasure from an option that is considered a treat (that 543 is, a source of special delight or pleasure) compared with the alternative option(s). 544 According to this author, consumers may indulge to enhance the self, to compensate 545 for something, or to ameliorate negative feelings, among other motivations.

546 The three most-liked (pleasurable) cookies (samples 3, 11, and 8) were placed in the 547 first dimension. As stated by Mehmeti and Xhoxhi (2014), the attributes for indulgence 
548 match those of pleasant foods and greater taste. These three samples all contained 549 chocolate, which is the most frequently craved food/ingredient (Rogers, \& Smit, 2000).

550 Craving for chocolate is not hunger dependent (Gibson \& Desmond, 1999), nor is it

551

552

553

554

555

556

557

558

559

560

561

562

563

564

565

566

567

568

569

570

571

572

573

574

575

576

577

578

579 easily satisfied by other foods. Consequently, it was not surprising that chocolate was a much looked-at ingredient when classifying the cookies. According to Marshall (2007), for most people, eating chocolate (including the anticipation of eating it) is highly pleasurable.

The second dimension separated two groups of motivations and occasions. The positive part of this dimension included more utilitarian motivations such as "When I want an easy-to-get sweet food," "When I want something filling," "When I want something for energy," and "As a nibble," and everyday eating occasions such as "At breakfast," "At work," "For mid-morning," "For mid-afternoon," and "With tea or coffee," and were related to familiarity as well as acceptability. Several studies have found that more familiar products were liked more (Kim, Jombart, Valentin, \& Kim, 2015). In indulgence-related literature, the terms "indulgence" and "utilitarian" are commonly regarded as opposites. However, Saldanha (2009) stated that for "mixed indulgences" (in which utilitarian attributes were added to hedonic ones), the products were perceived to be just as pleasant, but less sinful than pure indulgences.

The negative part of the second dimension included motivations related to exclusivity and prestige. According to Kivetz and Simonson (2002), indulgence in some products is closely related to both luxury and hedonics, often involving spending on items perceived as luxuries relative to one's means.

The left part of the map (Figure 3A) showed a few motivations and no eating occasions: "After doing exercise," "When I want something cheap," and "When I want something heathy," all placed in the positive half of the second dimension and related to healthiness. None of the three cookies placed in this area of the map (samples 5, 7, and 14) contain chocolate. The energy content of chocolate is commonly known to consumers because of its fat and sugar levels, but the participants were probably not fully aware of the fat or sugar content of these non-chocolate cookies.

In summary, development of cookies for indulgence should look at ingredients such as chocolate, which is extremely well-liked and is a driver for satisfying indulgencerelated motivations. Consumers generally find motivations for indulgence in familiar 
products, but in the case of new or unfamiliar products, the elements that appeal because of their exclusivity and luxury are also likely to satisfy consumers' inner motivations for indulgence.

583

\section{Conclusions}

585 The present exploratory studies of consumer perceptions of cookies with appealing 586 ingredients point to conclusions that merit further research. Study 1 showed that the 587 presence of visible (dark or milk) chocolate was the primary driver of cookie classification, followed by type of cookie, in both the package-examination and cookietasting scenarios. The qualitative analysis of the terms elicited from the consumers confirmed this (along with which samples were not very well-liked).

591 Study 2 confirmed that consumer perceptions of cookies containing visible dark or milk 592 chocolate (the most liked) were related to one major dimension representing 593 indulgence motivations and occasions. On the whole, consumers will choose well-liked cookies to indulge themselves. This applies both to familiar cookies and to exclusive cookies for special eating occasions. In this study, cookies with no chocolate were regarded as healthier, and cookies that were unfamiliar or not very well-liked seemed to elicit the lowest frequency of eating motivations and occasions.

598 These results should encourage studies of other food categories to gain greater insight 599 into consumer perception of indulgence in relation to food products.

600

\section{Acknowledgements}

602 The authors are grateful to the Spanish Ministry of the Economy and Competitiveness 603 for financial support (AGL-2017-75403-R) and for the Ramon y Cajal contract of Dr. 604 Tarrega, and gratefully acknowledge the financial support of EU FEDER funds. They 605 would also like to thank Raquel Baixauli and Jonás Lázaro from GRUPO SIRO for their 606 help, and Mary Georgina Hardinge and Laura Gatzkiewicz for assistance in correcting 607 the English manuscript.

608 609

\section{References}

610 
611

612

613

614

615

616

617

618

619

620

621

622

623

624

625

626

627

628

629

630

631

632

633

634

635

636

637

638

639

640

641

642

643

644

645

646

647

648

649

650

651

652

653

654

655

656

Ares, G., Deliza, R., Barreiro, C., Giménez, A., Gámbaro, A. (2010) Comparison of two sensory profiling techniques based on consumer perception. Food Quality and Preference, 21 (4), pp. 417-426.

Cargill ${ }^{\circledast}$ (2017). Indulgence.

https://cargillsaltinperspective.com/chocolate-cupcake-with-salted-caramel-icing/.

Accessed 04.08.17.

Cavannaugh, L. A. (2014). Because I (Don't) Deserve It: How Relationship Reminders and Deservingness Influence Consumer Indulgence. Journal of Marketing Research, $\mathrm{LI}$ (April), 218-232.

Cheng, Y.-H., Huang, M. C.-J., Chuang, S.-C., \& Ju, Y. R. (2015). Burger or yogurt? Indulgent consumption in impression management contexts. International Journal of Psychology, 50(5), 345-353.

Dehlholm, C. (2014). Projective mapping and napping. In P. Varela, \& G. Ares (Eds.), Novel Techniques in Sensory Characterization and Consumer Profiling (pp. 229-253). Boca Raton: CRC Press.

Deliza, R., \& MacFie, H. J. (1996). The generation of sensory expectation by external cues and its effect on sensory perception and hedonic ratings: a review. Journal of Sensory Studies, 11, 103-128.

Gardner, M. P., Wansink, B., Kim, J., \& Park, S.-B. (2014). Better moods for better eating?: How mood influences food choice. Journal of Consumer Psychology, 24, 320335.

Gibson, E. L., \& Desmond, E. (1999). Chocolate craving and hunger state: Implications for the acquisition and expression of appetite and food choice. Appetite, 32, 219-240.

Jack, F. R., O’Neill, J., Piacentini, M. G., \& Schröder, M. J. A. (1997). Perception of Fruit as a Snack: A Comparison with Manufactured Snack Foods. Food Quality and Preference, 8 (3), 175-182.

Kim, Y-K., Jombart, L., Valentin, D., \& Kim, K-O. (2015). Familiarity and liking playing a role on the perception of trained panelists: A cross-cultural study on teas. Food Research International, 71, 155-164.

Kivetz, R., \& Simonson, I. (2002). Self-Control for the Righteous: Toward a Theory of Precommitment to Indulgence. Journal of Consumer Research, 29, 199-217.

Luomala, H. T., Laaksonen, P., \& Leipamaa, H. (2004). How Do Consumers Solve Value Conflicts in Food Choices? An Empirical Description and Points For Theory-Building. NA - Advances in Consumer Research, 31, 564-570. 
657

658

659

660

661

662

663

664

665

666

667

668

669

670

671

672

673

674

675

676

677

678

679

680

681

682

683

684

685

686

687

688

689

690

691

692

693

694

695

696

697

698

699

700

701

702

703

Marcano, J., Ares, G., \& Fiszman, S. (2015). Comparison of partial and global projective mapping with consumers: A case study with satiating cheese pies. Food Research International, 67, 323-330.

Marshall, S. (2007). Chocolate: Indulgence or medicine? Pharmaceutical Journal, 278, 399-401.

Mehmeti, G., \& Xhoxhi, O. (2014). Future Food Trends. Annals. Food Science and Technology, on-line access.

http://www.afst.valahia.ro/docs/issues/2014/issue2/full/section5/s05 w03 full.pdf/, accessed 11.11.16.

Merriam-Webster Dictionary. (2017). https://www.merriam-webster.com / Accessed 12.30 .16

Meyners, M. \& Castura, J. C. (2014). Check-All-That-Apply Questions. In: In P. Varela, \& G. Ares (Eds.), Novel Techniques in Sensory Characterization and Consumer Profiling (pp. 271-306). Boca Raton: CRC Press.

Meyners, M., Castura, J. C. \& Carr, B. T. (2013) Existing and new approaches for the analysis of CATA data. Food Quality and Preference, 30, 309-319.

Miao, L., \& Mattila, A. S. (2013). Impulse Buying in Restaurant Food Consumption. Journal of Foodservice Business Research, 16, 448-467.

Pagès, J. (2005). Collection and analysis of perceived product inter-distances using multiple factor analysis: Application to the study of 10 wines from the Loire Valley. Food Quality and Preference, 16, 642-649.

Palmer, S. (2008). Healthy Indulgence: A Best of Both Worlds Approach to Eating. Today's Dietitian, on line edition.

http://www.todaysdietitian.com/newarchives/082508p62.shtm /Accessed 12.11.16.

Pool, E., Brosch, T., Delplanque, S., \& Sander, D. (2014). Stress Increases Cue-Triggered "Wanting" for Sweet Reward in Humans. American Psychological Association, 41 (2), 128-136.

Ramanathan, S., \& Williams, P. (2007). Immediate and Delayed Emotional Consequences of Indulgence: The Moderating Influence of Personality Type on Mixed Emotions. Journal of Consumer Research, 34(2), 212-223

Robert, P., \& Escoufier, Y. (1976). A unifying tool for linear multivariate statistical methods: The RV-coefficient. Applied statistics, 25 (3), 257-265.

Rogers, P. J., \& Smit, H. J. (2000). Food craving and food "addiction": A critical review of the evidence from a biopsychosocial perspective. Pharmacology, Biochemistry and Behavior, 66, 3-14. 
Saldanha, N. (2009). PhD dissertation thesis. On-line accessed on 04/14/2017.

706 http://opim.wharton.upenn.edu/risk/library/WP2009-andanha_MixedIndulgences.pdf

707

708 Vidal, L., Ares, G., \& Gimenez, A. (2013). Projective techniques to uncover consumer 709 perception: Application of three methodologies to ready-to-eat salads. Food Quality 710 and Preference, 28, 1-7.

711 


\section{$714 \quad$ Figure captions}

715 Figure 1. Multiple factor analysis of the projective mapping data from the cookie 716 packages task; (A) and (C): sample maps; (B) and (D): terms elicited from consumers $717(n=90) ;(A)$ and (B): plots corresponding to dimensions 1 and 2; (C) and (D): plots 718 corresponding to dimensions 3 and 4

720 Figure 2. Multiple factor analysis of the projective mapping data from the cookie 721 tasting task; $(A)$ and $(C)$ : sample maps; (B) and (D): terms elicited from consumers 722 ( $n=90)$; (A) and (B): plots corresponding to dimensions 1 and 2; (C) and (D): plots 723 corresponding to dimensions 3 and 4

724

725 Figure 3. Multiple factor analysis of the motivations and occasions ticked by consumers $726(n=100)$ in the CATA questionnaire for the 8 cookie samples selected from the 727 clustering task. Acceptability, perceived healthiness, and familiarity scores were used 728 as supplementary variables. (A) Map of terms; motivations are in red and occasions in 729 blue letters. (B) Map of samples. 
Table 1. Information and characteristics of the images on the cookie packages.

\begin{tabular}{|c|c|c|c|}
\hline Code & Name & Image & $\begin{array}{l}\text { Ingredients/ } \\
\text { composition }\end{array}$ \\
\hline 1 & $\begin{array}{l}\text { Soft Baked, Dark Chocolate } \\
\text { Chunk Cookies }\end{array}$ & Broken half cookie (enlarged) & \\
\hline 2 & Luxury Cookies & Two cookies (enlarged) & $\begin{array}{l}\text { Double chocolate "aux } \\
\text { généreuse pépites au } \\
\text { chocolat" (in French) }\end{array}$ \\
\hline 3* & Cookies with chocolate chips & One and a half cookies (real size) & $37 \%$ chocolate \\
\hline $4^{*}$ & PIM'S L'Original Orange & One cookie (enlarged) & Since 1846 \\
\hline 5* & Fruit \& form & $\begin{array}{l}\text { Half a cookie and fresh berries } \\
\text { (serving suggestion) }\end{array}$ & $\begin{array}{l}\text { Fruit filling } 36 \% \\
\text { Crunchy bars }\end{array}$ \\
\hline 6 & Raspberry tartlets & $\begin{array}{l}\text { One and a half cookies (smaller than } \\
\text { real size) and two fresh raspberries } \\
\text { (serving suggestion) }\end{array}$ & \\
\hline 7* & Pure butter shortbread & $\begin{array}{l}\text { Three cookies (smaller than real } \\
\text { size) }\end{array}$ & $\begin{array}{l}\text { Product of Scotland, } \\
\text { established } 1898\end{array}$ \\
\hline $8^{*}$ & Tortina White & $\begin{array}{l}\text { One and a half cookies (real size), a } \\
\text { piece of white chocolate and } \\
\text { hazelnuts }\end{array}$ & \\
\hline 9 & $\begin{array}{l}\text { Cookies with a white } \\
\text { chocolate tablet }\end{array}$ & $\begin{array}{l}\text { Three cookies (real size) (serving } \\
\text { suggestion) }\end{array}$ & $\begin{array}{l}\text { With authentic Swiss } \\
\text { chocolate } \\
\text { Nutritional facts }\end{array}$ \\
\hline $10^{*}$ & Air Reve de Vanille & $\begin{array}{l}\text { Three "floating" cookies (real size), } \\
\text { vanilla flower and vanilla bean }\end{array}$ & Since 1928 \\
\hline $11 *$ & $\begin{array}{l}\text { Cookie with dark chocolate } \\
\text { tablet }\end{array}$ & $\begin{array}{l}\text { Two and a half cookies (smaller than } \\
\text { real size) }\end{array}$ & Crunchy \\
\hline 12 & $\begin{array}{l}\text { Chocolate coated wafers } \\
\text { with hazelnut filling }\end{array}$ & Two and a half cookies (real size) & Crunchy \\
\hline 13 & No description & $\begin{array}{l}\text { One broken cookie (smaller than } \\
\text { real size) with small pieces exploding }\end{array}$ & \\
\hline $14^{*}$ & Cocoa filled wafers & Two cookies (smaller than real size) & \\
\hline 15 & Filled Wafers. Cream flavor & Two cookies (smaller than real size) & \\
\hline 16 & Puff pastry cookies & Nine cookies (smaller than real size) & \\
\hline 17 & Butter cookies with almonds & $\begin{array}{l}\text { Three "floating" cookies (real size) } \\
\text { and some peeled almonds }\end{array}$ & $\begin{array}{l}\text { Swiss excellence since } \\
1910\end{array}$ \\
\hline
\end{tabular}

\footnotetext{
* Samples selected for Study 2 through hierarchical clustering analysis
} 
$735(\mathrm{n}=90)$ in the description task following the Projective Mapping performed with the 736 packages. The numbers in parentheses are expressed as percentages.

\begin{tabular}{|c|c|c|}
\hline Qualitative categories, subcategories, and examples of terms & $\begin{array}{l}\text { Number of } \\
\text { terms }\end{array}$ & $\begin{array}{l}\text { Number of } \\
\text { mentions }\end{array}$ \\
\hline NON-SENSORY TERMS & 66 (73.3\%) & $2127(85.1 \%)$ \\
\hline $\begin{array}{l}\text { Package characteristics } \\
\text { Different; Made of plastic, * paperboard, or paper;* } \\
\text { Attractive;* Bag; With little information; Big; Weak; } \\
\text { Conventional; Color contrast; Dark colors; Intense colors; I } \\
\text { like the package; I don't like the package }\end{array}$ & $17(18.9 \%)$ & $118(4.7 \%)$ \\
\hline $\begin{array}{l}\text { Ingredients } \\
\text { Chocolate; }{ }^{*} \text { Chocolate chips; }{ }^{*} \text { White chocolate;* Dark } \\
\text { chocolate;* Without chocolate; }{ }^{*} \text { Fruit/ jam;* Butter;* } \\
\text { Nuts;* Vanilla;* Cream;* Sugar on the surface;* etc. }\end{array}$ & $14(15.6 \%)$ & $1073(42.9 \%)$ \\
\hline $\begin{array}{l}\text { Type of cookie } \\
\text { Wafer; }{ }^{*} \text { Chocolate chip cookie;* Tea cookie;* Filled;* } \\
\text { Chocolate covered; With a chocolate tablet; }{ }^{*} \text { Soft; }{ }^{*} \\
\text { Sandwich; }{ }^{*} \text { Tartlet* }\end{array}$ & $9(10.0 \%)$ & $566(22.6 \%)$ \\
\hline $\begin{array}{l}\text { Uses } \\
\text { For breakfast; }{ }^{*} \text { As an afternoon snack; }{ }^{*} \text { For eating with tea } \\
\text { or coffee; }{ }^{*} \text { For special occasions; }{ }^{*} \text { For children; etc. }\end{array}$ & $7(7.8 \%)$ & $\begin{array}{l}82 \\
(3.3 \%)\end{array}$ \\
\hline $\begin{array}{l}\text { Others } \\
\text { Traditional;* Different; }{ }^{*} \text { Imported; * Luxury; Healthier; } \\
\text { Unhealthy; High calorie; } \text { Satiating; * Store brand;* high- } \\
\text { quality, known, unknown brand; Cheap;* Expensive; I } \\
\text { would buy it; I wouldn't buy it, etc. }\end{array}$ & $20(22.0 \%)$ & $288(11.5 \%)$ \\
\hline SENSORY TERMS & $24(26.7 \%)$ & 373 (14.9\%) \\
\hline $\begin{array}{l}\text { Appearance } \\
\text { Rectangular;* Round;* Dark color; }{ }^{*} \text { Big; }{ }^{*} \text { Without filling;* } \\
\text { Light; Small; Thick; Decorated; Without coating }\end{array}$ & $10(13.3 \%)$ & $156(6.2 \%)$ \\
\hline
\end{tabular}

$\begin{array}{lll}\text { Flavor/texture } & 9(10.0 \%) & 72(3.0 \%)\end{array}$

Light; * Different flavor; * Sweet; Crunchy; Dry; Hard;

Spongy; Dense; Different texture

\begin{tabular}{llc}
\hline $\begin{array}{l}\text { Hedonics } \\
\text { I like it; }{ }^{*} \text { I don't like it; * Tempting; Attractive; Good flavor }\end{array}$ & 5 (5.6\%) & $145(5.8 \%)$ \\
\hline TOTAL & $\mathbf{9 0 ~ ( 1 0 0 \% )}$ & $\mathbf{2 5 0 0 ~ ( 1 0 0 \% )}$ \\
\hline
\end{tabular}


740 Table 3. Categories and subcategories of the terms generated by the consumers ( $\mathrm{n}=$ 74190 ) in the description task following the projective mapping performed while tasting 742 the cookies. List of terms (non-exhaustive), number of terms, and mentions. The 743 numbers in parentheses are expressed as percentages.

\begin{tabular}{|c|c|c|}
\hline Qualitative category and terms & $\begin{array}{l}\text { Number of } \\
\text { terms }\end{array}$ & $\begin{array}{l}\text { Number of } \\
\text { mentions }\end{array}$ \\
\hline NON-SENSORY TERMS & $37(47.5 \%)$ & $1770(65.9 \%)$ \\
\hline $\begin{array}{l}\text { Ingredients } \\
\text { Chocolate; }{ }^{*} \text { White, }{ }^{*} \text { dark* chocolate; Cream; Butter; } \\
\text { Chocolate chips; }{ }^{*} \text { Fruit/ jam;* Nuts; }{ }^{*} \text { Vanilla;* etc. }\end{array}$ & $15(18.8 \%)$ & $952(35.4 \%)$ \\
\hline $\begin{array}{l}\text { Type of cookie } \\
\text { Wafer; }{ }^{*} \text { Chocolate chip cookie;* Tea cookie;* Coated; } \\
\text { Filled; }{ }^{*} \text { With chocolate tablet; }{ }^{*} \text { Soft; }{ }^{*} \text { Sandwich;* } \\
\text { Tartlet.* }\end{array}$ & $9(11.2 \%)$ & $607(22.6 \%)$ \\
\hline $\begin{array}{l}\text { Uses } \\
\text { For breakfast; As an afternoon snack; For eating with } \\
\text { coffee or tea; For special occasions. }\end{array}$ & $4(5.0 \%)$ & $50(1.9 \%)$ \\
\hline $\begin{array}{l}\text { Others } \\
\text { Different; I would buy it; I wouldn't buy it; * } \\
\text { Traditional;* Imported; Luxury; Healthy; Satiating; not } \\
\text { very satiating; Industrially processed. }\end{array}$ & $10(12.5 \%)$ & $162(6.0 \%)$ \\
\hline SENSORY TERMS & $41(52.5 \%)$ & $914(34.0 \%)$ \\
\hline $\begin{array}{l}\text { Flavor/texture } \\
\text { Crunchy;* Sandy; }{ }^{*} \text { Dense;* Spongy; }{ }^{*} \text { Light;* Brittle; } \\
\text { Cinnamon*, Mint*, Butter, or Honey taste; Dry; Moist; } \\
\text { Tender; Fatty; Difficult to chew; Easy to chew; Sweet; } \\
\text { Intense flavor; Bitter; etc. }\end{array}$ & $27(33.8 \%)$ & $501(18.7 \%)$ \\
\hline $\begin{array}{l}\text { Appearance } \\
\text { Big;* Thin;* Without filling;* Rectangular;* Round;* } \\
\text { Without coating; Light color; Dark color; Small; Thick. }\end{array}$ & $10(12.5 \%)$ & $209(7.8 \%)$ \\
\hline $\begin{array}{l}\text { Hedonics } \\
\text { I like it, I don't like it; * Attractive; Not attractive; Good } \\
\text { flavor. }\end{array}$ & $5(6.2 \%)$ & $205(7.6 \%)$ \\
\hline TOTAL & $80(100 \%)$ & $2686(100 \%)$ \\
\hline
\end{tabular}

* Terms with significantly different frequencies of mention between samples 
747 Table 4. Sample clusters in the Package scenario (the samples were packaged, the 748 cookies were not tasted) and Cookie scenario (after tasting the cookie samples without 749 seeing the packaging)

\begin{tabular}{ll}
\hline Clustered samples & \\
\hline \multicolumn{1}{c}{ Package scenario } & Cookie scenario * \\
\hline $1,2,3$ & $1,2, \mathbf{3}$ \\
$4,5,6$ & $\mathbf{4}$ \\
$7,10,17$ & $\mathbf{5}, 6$ \\
8,9 & $\mathbf{7}, 16,17$ \\
11,13 & $\mathbf{8}, \mathbf{9}$ \\
12,14 & $\mathbf{1 0}$ \\
15 & $\mathbf{1 1}, 13$ \\
16 & $12, \mathbf{1 4}, 15$ \\
\hline
\end{tabular}

750

* Numbers in bold are the cookies selected for the assessment of acceptability, familiarity, and healthiness expectations (see section 3.2)

752 
Table 5. Mean acceptability, perceived healthiness, and familiarity scores of the 8 754 cookies selected as representative of each type of cookie, as determined by consumers $755 \quad(n=100)$.

756

\begin{tabular}{llll}
\hline Sample & $\begin{array}{l}\text { Acceptability* } \\
\text { (9-point scale) }\end{array}$ & $\begin{array}{l}\text { Healthiness* } \\
\text { (9-point scale) }\end{array}$ & $\begin{array}{l}\text { Familiarity* } \\
\text { (10-cm scale) }\end{array}$ \\
\hline 11 & $7.5(1.5) \mathrm{a}$ & $4.3(1.9) \mathrm{b}$ & $8.3(1.7) \mathrm{a}$ \\
8 & $7.4(1.8) \mathrm{a}$ & $2.9(1.9) \mathrm{c}$ & $3.8(2.9) \mathrm{cd}$ \\
3 & $7.3(1.6) \mathrm{a}$ & $3.6(1.8) \mathrm{bc}$ & $8.5(1.8) \mathrm{a}$ \\
14 & $6.5(1.6) \mathrm{ab}$ & $4.4(1.8) \mathrm{b}$ & $8.2(1.7) \mathrm{a}$ \\
7 & $5.9(2.1) \mathrm{bc}$ & $4.0(1.8) \mathrm{b}$ & $4.1(3.0) \mathrm{c}$ \\
4 & $5.6(2.1) \mathrm{bc}$ & $4.0(1.9) \mathrm{b}$ & $5.5(3.2) \mathrm{b}$ \\
5 & $5.6(2.5) \mathrm{bc}$ & $5.4(1.9) \mathrm{a}$ & $2.8(2.4) \mathrm{d}$ \\
10 & $5.1(2.1) \mathrm{c}$ & $3.8(1.9) \mathrm{b}$ & $2.9(2.3) \mathrm{d}$ \\
\hline F-ratio & 15.6 & 15.6 & 72.3 \\
\hline $\mathrm{p}$ & $<0.0001$ & $<0.0001$ & $<0.0001$ \\
\hline
\end{tabular}

*Different letters in the same column denote significant differences according to the Tukey test $758 \quad(\mathrm{p}<0.05)$.

759 Figures in parenthesis are the standard deviations

760

761

762

763

764 
(A)

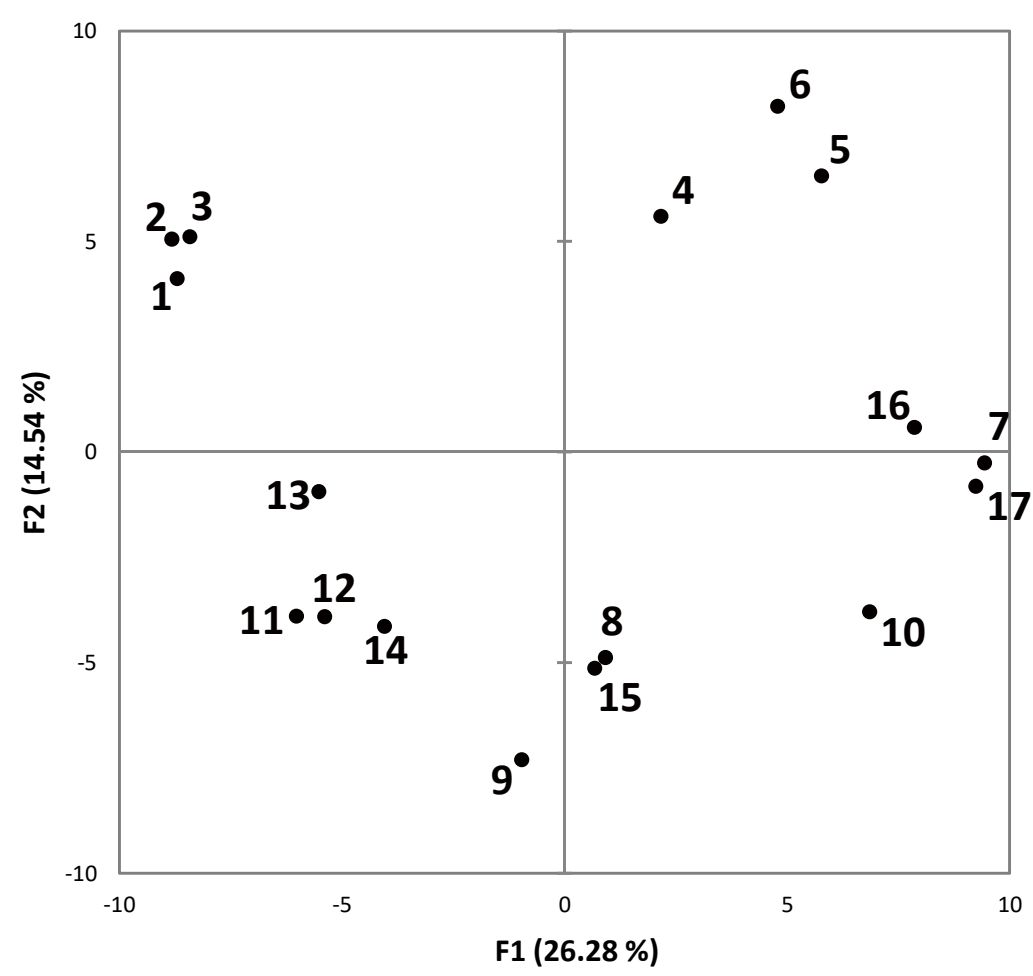

(B)

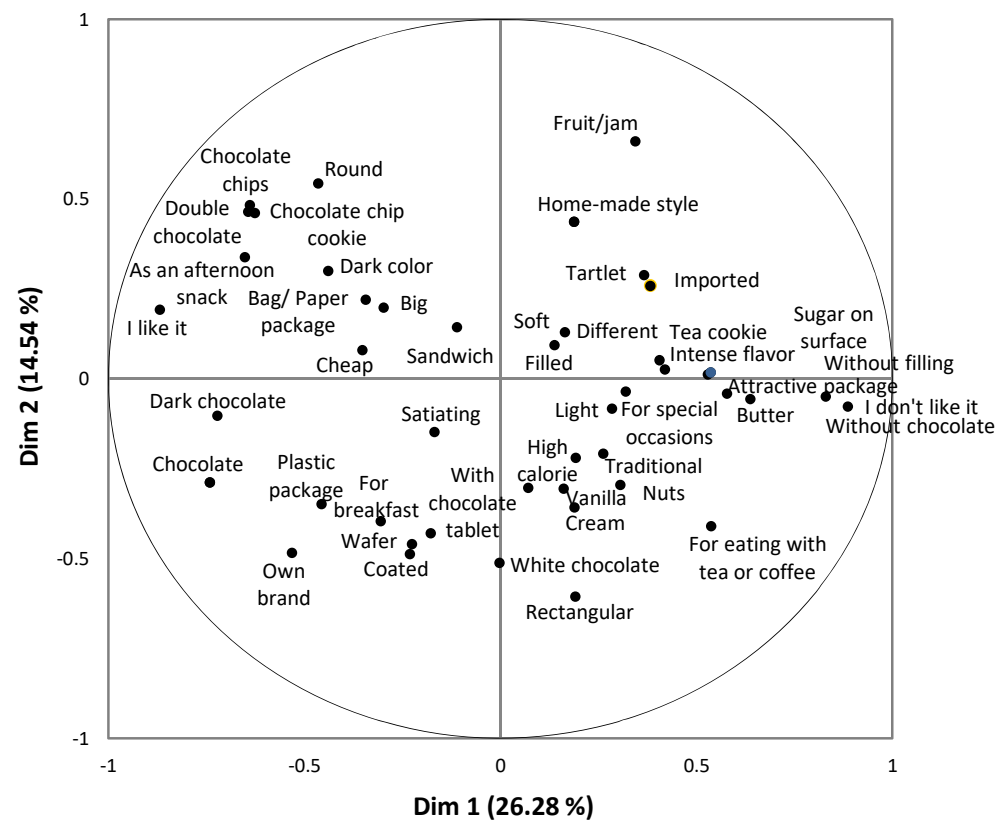

(C) 


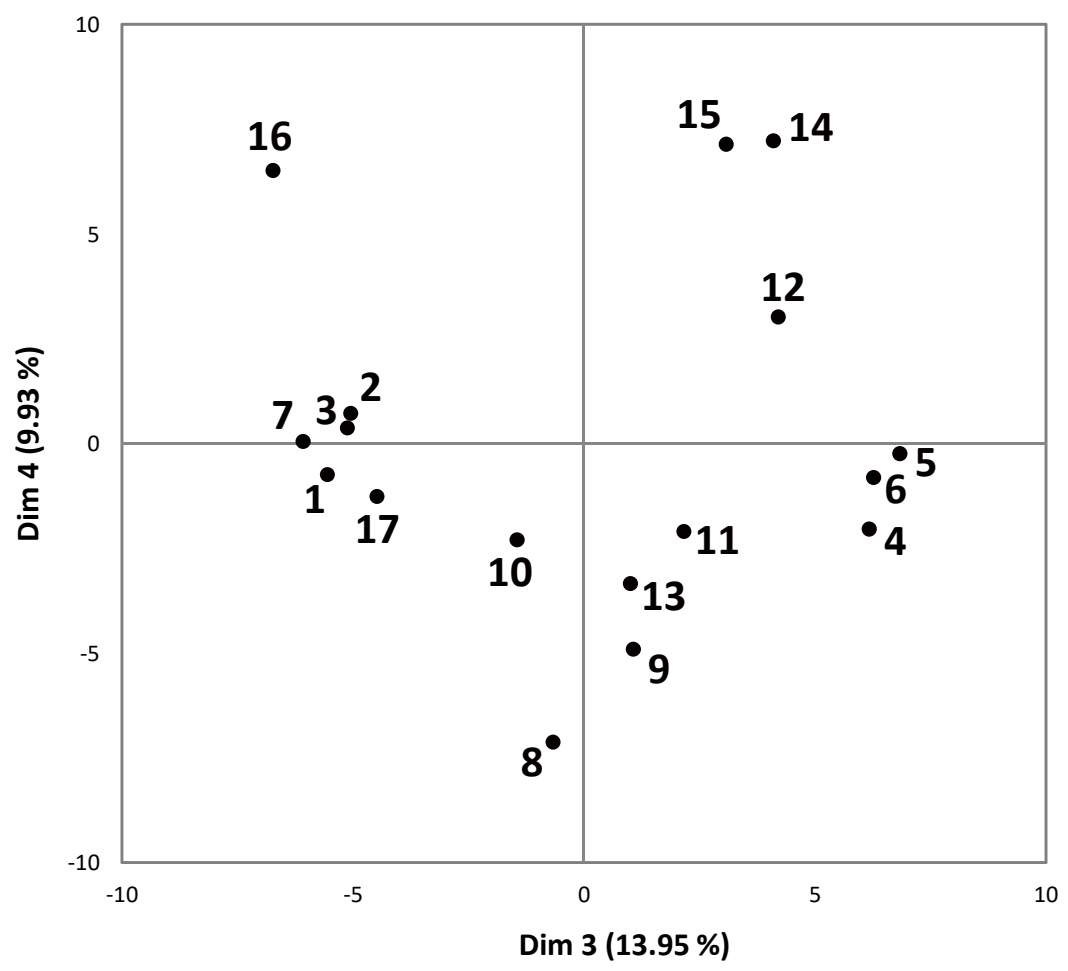

(D)

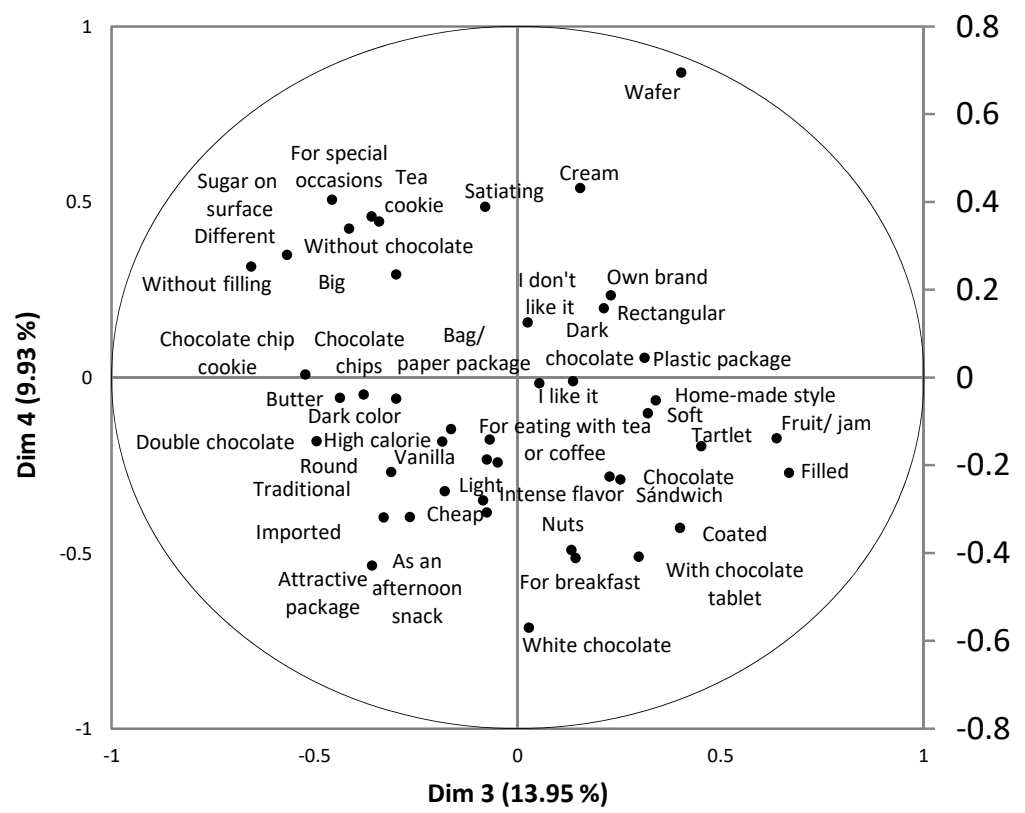


(A)

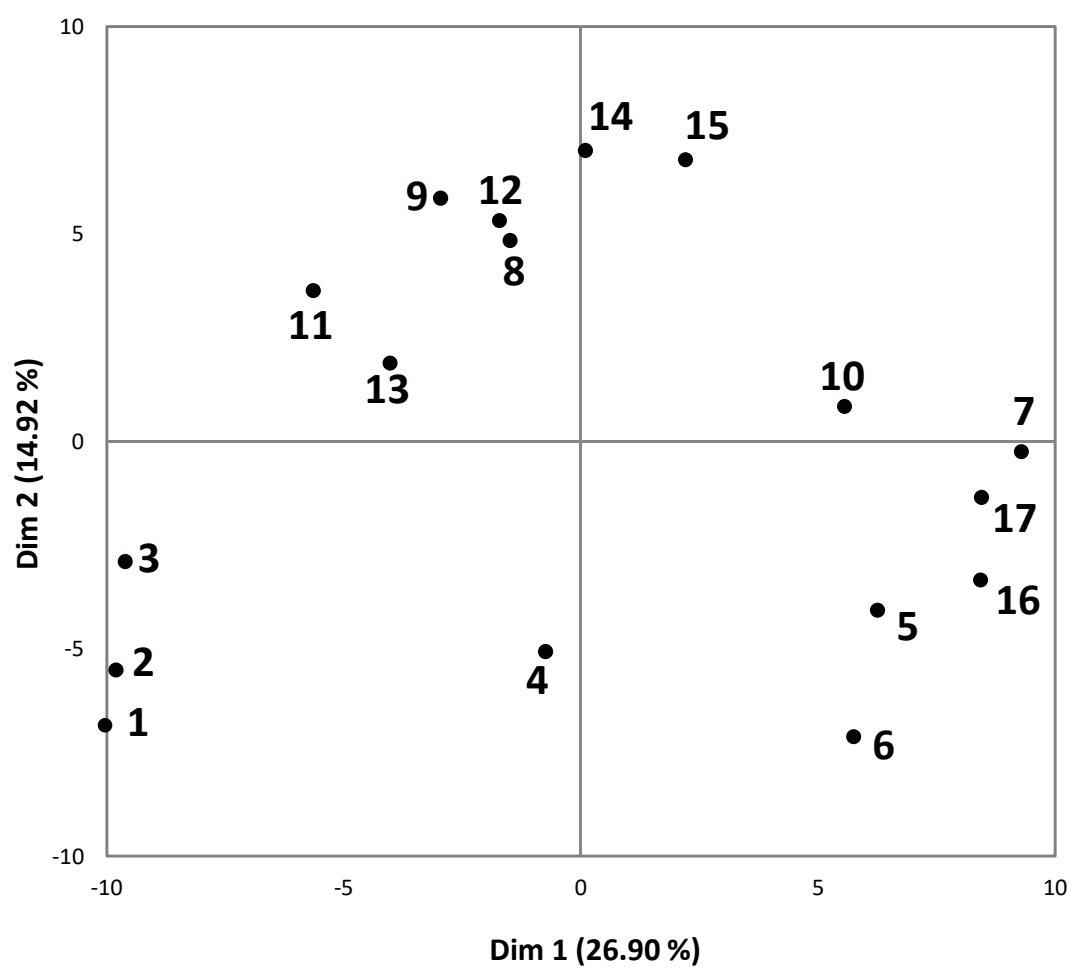

(B)

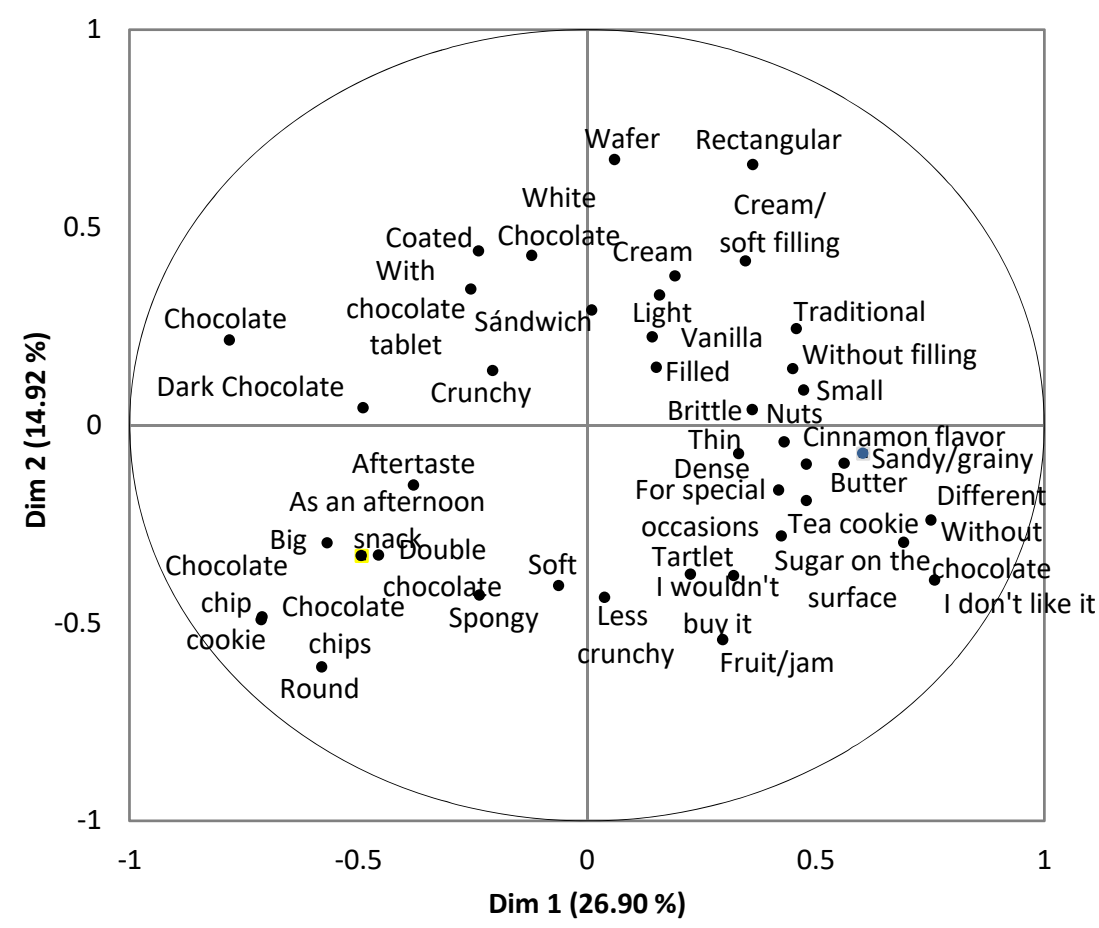


(C)

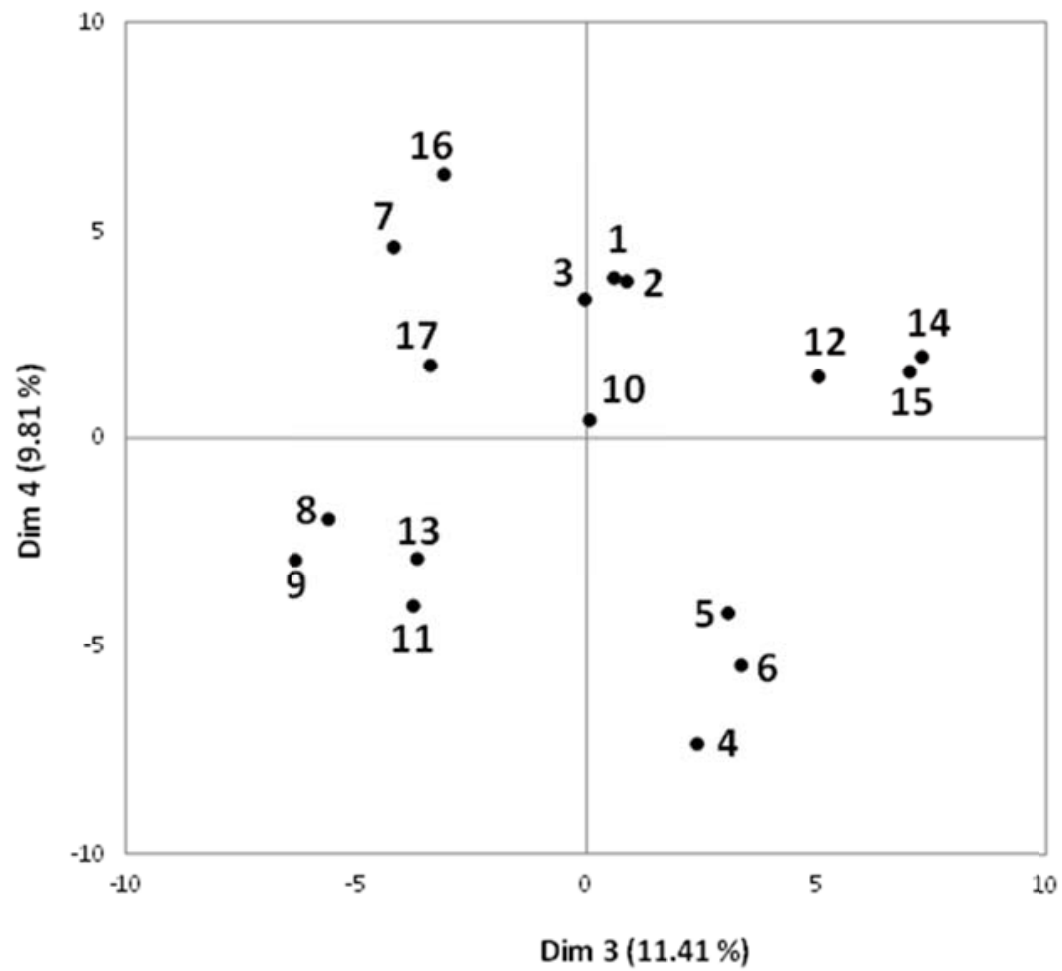

(D)

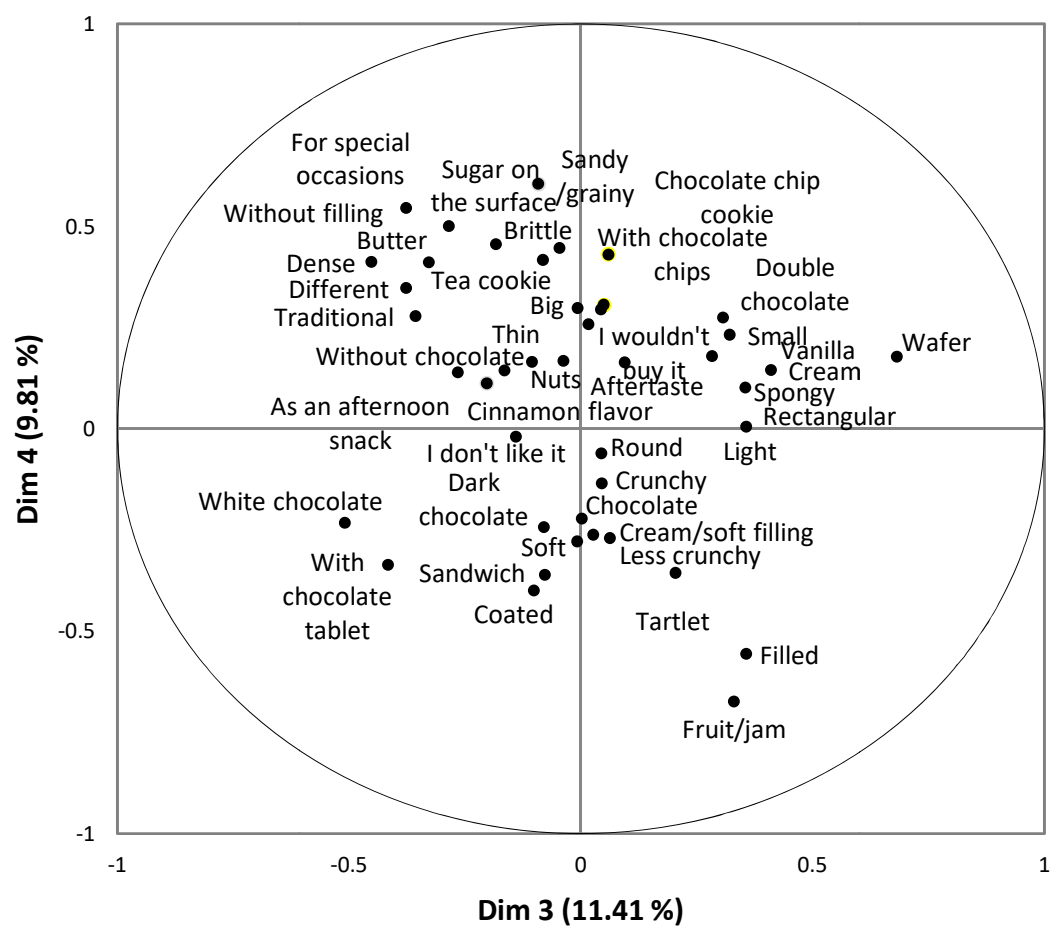


(A)

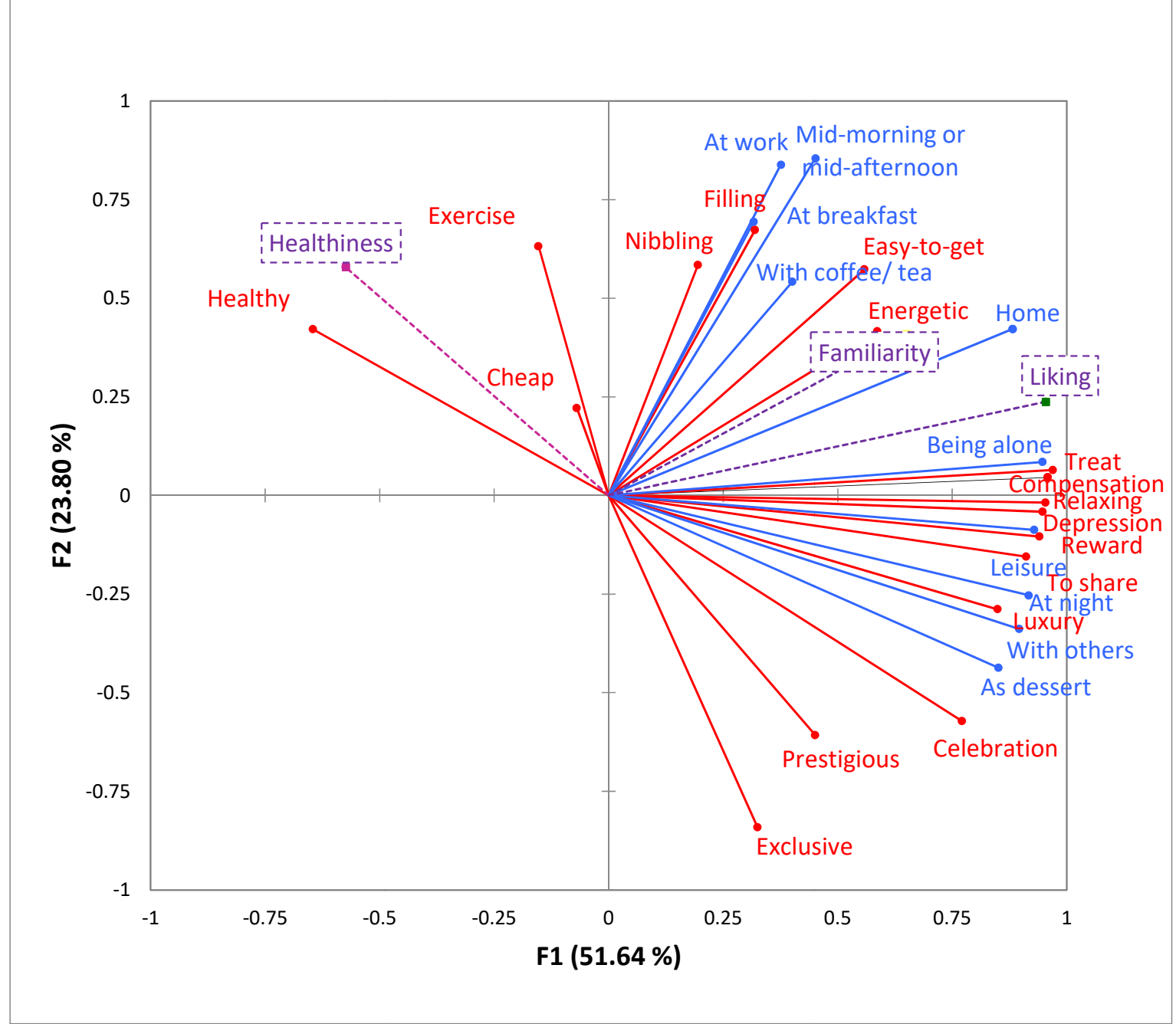

(B)

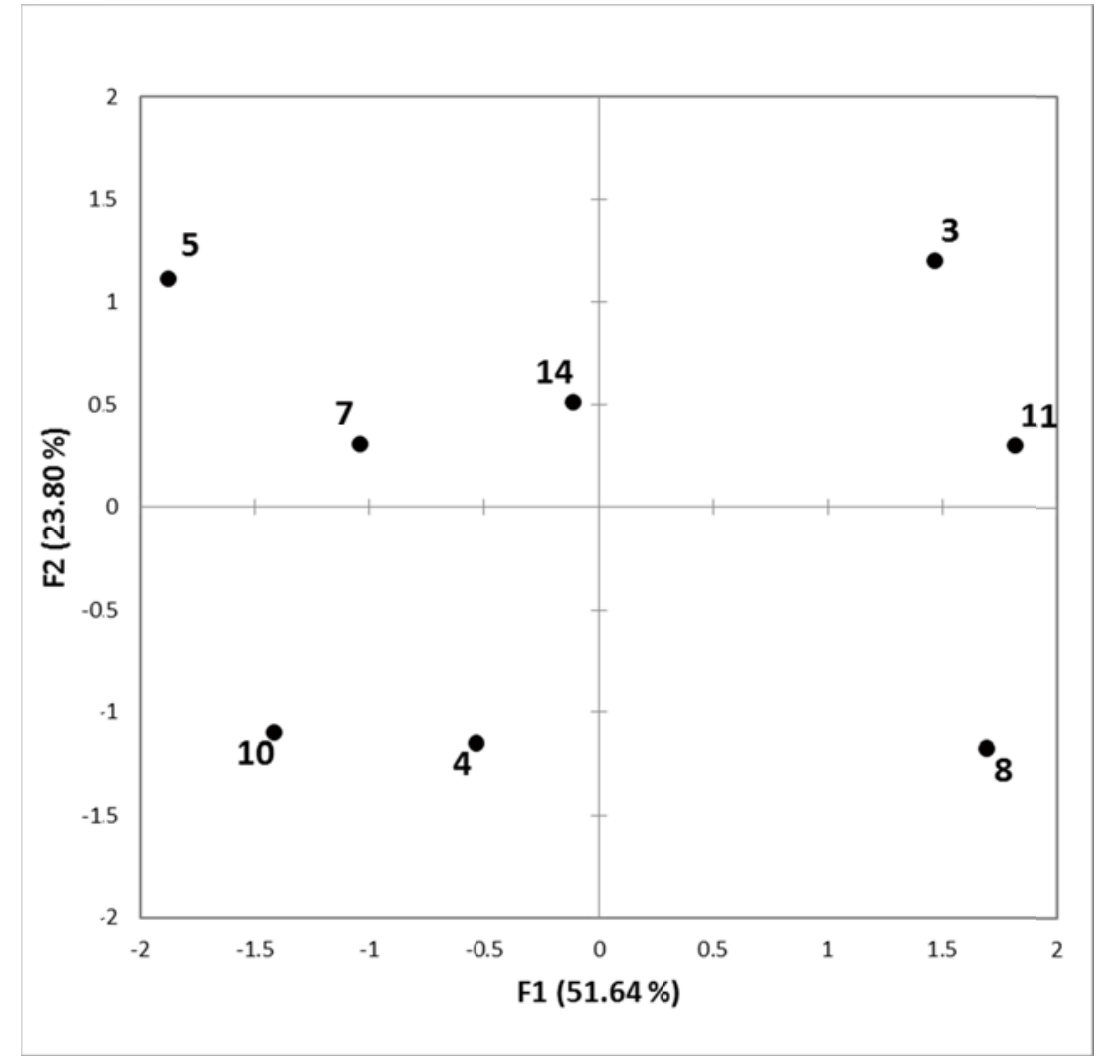


